\title{
Inhibition of return for objects and locations in static displays
}

\author{
E. C. LEEK, I. REPPA, and S. P. TIPPER \\ University of Wales, Bangor, Wales
}

\begin{abstract}
When orienting attention, inhibition mechanisms prevent the return of attention to previously examined stimuli. This inhibition of the return of attention (IOR) has been shown to be associated additively with location- and object-based representations. That is, when static objects are attended, IOR is associated with both the object and the location cued, and hence IOR is larger than when only spatial location is attended. Recently McAuliffe, Pratt, and O'Donnell (2001) failed to observe such additive effects except under a narrow set of conditions (at short cue-target intervals and using mixed blocks in which object- and pure location-based effects were probed in the same display). The present study shows that additive IOR effects are observed under conditions that violate all of these boundary conditions. The results also show that IOR is modulated by internal structural properties of objects. These findings are consistent with the hypothesis that IOR operates over functionally independent objectand location-based frames of reference.
\end{abstract}

In order to search a complex scene for a particular object it is necessary that attention be moved until the target object is found. Posner and Cohen (1984) argued that an important mechanism enabling such search is inhibition. That is, after attention is withdrawn from one spatial location, it is inhibited, momentarily, from returning there. They termed this effect inhibition of return (IOR).

The procedures developed by Posner and Cohen (1984), to demonstrate IOR, typically involve displays in which two boxes are presented at equal distances to the left and right of a central fixation point. One of the boxes is cued with a luminance increment (although participants are informed that this is irrelevant to the task) and then a further cue is briefly presented at fixation. Finally a target is shown in either the same box as the initial cue (cued location) or in the other box (uncued location). IOR is reflected in the finding that the time taken to detect targets is slower at cued locations than at uncued locations.

A central issue concerning IOR is the frame of reference with which it interacts. Initial accounts suggested that spatial locations are inhibited (e.g., Maylor, 1985), but subsequent work has shown that inhibition may also be based on objects and not solely on spatial locations (e.g., Jordan \& Tipper, 1998; Reppa \& Leek, in press; Tipper, Driver, \& Weaver, 1991). This object-based account of IOR predicts that after attending to an object, if the object were to move, the inhibition associated with it

This research was supported by Project Grant R000239512 from the Economic and Social Research Council (ESRC, U.K.), awarded to E.C.L. The authors thank Jeremy Wolfe, Jim McAuliffe, and Yuji Takeda for their helpful comments on an earlier version of the paper. Correspondence should be addressed to E. C. Leek, Centre for Cognitive Neuroscience, School of Psychology, University of Wales, Bangor, Gwynedd, LL57 2AS, Wales (e-mail: e.c.leek@bangor.ac.uk). should also move. In a series of studies, Tipper and colleagues (Tipper et al., 1991; Tipper, Jordan, \& Weaver, 1999; Tipper, Weaver, Jerreat, \& Burak, 1994) demonstrated that indeed, after cuing attention to an object, processing of a target presented on the cued object was impaired even after the object had moved $90^{\circ}$ from its original location. In addition, Tipper et al. (1999; Tipper et al., 1994) showed that both object- and location-based IOR could be observed simultaneously. That is, after cuing, inhibition is found simultaneously at the location originally cued and on the object that has moved to a new location.

Several studies have also shown that object-based IOR effects in dynamic displays appear to be somewhat smaller (approximately $20 \mathrm{msec}$ ) than the typical effects produced by cuing static box displays (approximately $40 \mathrm{msec}$; see Müller \& von Mühlenen, 1996). In order to account for this fact, a number of researchers (e.g., Jordan \& Tipper, 1998; Tipper \& Weaver, 1998; Weaver, Lupiáñez, \& Watson, 1998) have pointed out that the two putative pure components of IOR (location and object), when combined, summed up to the 40-msec effects observed when cuing static box displays. Therefore the larger effects found in static displays might arise not because locationbased effects are larger, but rather because objects (squares) are always cued, and hence the resulting effects are likely to reflect a summation of location- and object-based IOR.

Jordan and Tipper (1998) tested this "summation" hypothesis using a static display IOR paradigm. In their study, participants were presented with arrays of features that when combined in one manner produced illusory white Kanisza squares, but when rearranged produced no perceptible object. In the same displays targets were presented either on objects or at empty locations. The results 
showed that IOR was significantly larger when objects were cued, supporting the idea that object- and locationbased IOR could be additive.

However, some recent work by McAuliffe, Pratt, and O'Donnell (2001) has questioned this proposal. In Experiment 1 they replicated the Jordan and Tipper (1998) finding that IOR is significantly larger when cues and targets are presented on an object (e.g., placeholder) in a static display, relative to when they are presented at empty locations in the same display (e.g., outside of the placeholders). In contrast, when object-present and objectabsent IOR was probed using separate displays (Experiments 2 and 3), a difference in the magnitude of IOR between object-present and object-absent conditions was only found using mixed blocks of trials with a short (400-msec) cue-target (CT) stimulus onset asynchrony (SOA) (McAuliffe et al., 2001, Experiment 3). At longer SOAs (600 and $800 \mathrm{msec}$ ) and with blocked presentations of object-present and object-absent displays (Experiments 2 and 3 ), no difference in IOR was found.

These findings seem to challenge the hypothesis that IOR for objects is additive with IOR for locations: If it were, then IOR effects should be greater in cued object locations than in empty spatial locations regardless of whether both object- and location-based effects are measured from the same or from different displays (e.g., as in Jordan \& Tipper, 1998), or whether mixed- or blockedtrial designs are used (as in McAuliffe et al., 2001, Experiments 2 and 3). On the basis of their data, McAuliffe et al. argued that in fact IOR may be better accounted for in terms of a model that assumes a context-sensitive "single-component" mechanism, rather than in terms of additive, functionally distinct, location- and objectbased inhibitory components.

In this paper we present new data on this issue and examine why additive effects of location-and object-based inhibition were found only under highly restricted conditions by McAuliffe et al. (2001). In studies of IOR it is somewhat surprising that object-based effects are ever observed. This is because objects in the stimulus displays are irrelevant to the main task of detecting a transient onset stimulus. Jordan and Tipper (1999) noted this point and suggested that object-based IOR may decline as an experiment continues because subjects habituate to the irrelevant stimulus. They suggested, and observed some data to support, the notion that the salience (e.g., complexity, variability) of the object might be important for observing object-based IOR. For example, in Jordan and Tipper (1998), and in the McAuliffe et al. replication (Experiment 1), targets could be presented at one of four loci around fixation. In contrast, in the failed replications (McAuliffe et al., 2001, Experiments 2 and 3) targets were presented only at one of two loci to the left and right of fixation. These factors might have played an important role in the different patterns of results found in the Jordan and Tipper (1998) and McAuliffe et al. studies.

In the present study we examined object- and locationbased IOR in static displays when object trials are in separate blocks from pure spatial location trials. In addition, to increase the salience of the objects in the displays, the following were manipulated:

1. Targets could be presented at six loci around fixation.

2. On cued-object trials two kinds of objects could be presented: one containing an internal part boundary and the other consisting of a single component (Reppa \& Leek, in press).

3. Objects could be presented at either of two orientations $\left(+45^{\circ}\right.$ and $\left.-45^{\circ}\right)$.

4. Two CT SOAs were utilized ( 820 and $1,220 \mathrm{msec}$ ).

Critically, these experimental parameters violate all of the boundary conditions for observing greater objectthan purely location-based IOR reported by McAuliffe et al. (2001). That is, in the present study, (1) object- and pure location-based conditions were not probed in the same display, (2) the two conditions were presented in separate blocks of trials, and (3) relatively long SOAs were used.

The predictions were straightforward: If McAuliffe et al. (2001) are right, we would not expect to find a difference in the magnitude of IOR between object-present and object-absent conditions. In contrast, the additive effects model predicts that IOR should be greater in objectpresent than in object-absent trials.

In addition, to support the proposal that there are separate object- and location-based IOR mechanisms, it is also necessary to show properties of IOR that are specific to just one of these forms of representation. To this end we also investigated the spread of IOR across object structure. Reppa and Leek (in press) have recently demonstrated that the internal features of objects may modulate IOR. That is, IOR is larger when cues and targets are separated by an internal part boundary than when they are located on the same shape component. A further aim of this study was to examine whether this modulation is also found using different task parameters. If so, this would provide further evidence that object- and locationbased IOR are functionally dissociable.

\section{METHOD}

\section{Participants}

Thirty-four psychology undergraduates between 18 and 33 years from the University of Wales, Bangor, participated in this experiment in exchange for two course credits. They all reported normal or corrected-to-normal vision.

\section{Apparatus and Stimuli}

Stimuli were presented on a 14-in. monitor connected to a Power Macintosh. Randomization and presentation of the stimuli, as well as recording of the participants' RTs, were controlled using PsyScope software (Version 1.2.4; Cohen, MacWhinney, Flatt, \& Provost, 1993). Responses were made through a single letter key on a standard Apple keyboard connected to the computer.

Stimuli for the object-present condition were the outline (black) L-shaped objects used in Reppa and Leek (in press, Experiment 2). The two L-shapes were simultaneously presented on each side of a fixation cross (Figure 3) against a light gray background. The stimuli were presented in two possible orientations: tilted either $+45^{\circ}$ or 
$-45^{\circ}$ from the vertical meridian (Figure 1). When the L-shapes were tilted $+45^{\circ}$, the short rectangles were positioned approximately above and below fixation, and when they were tilted $-45^{\circ}$, the short rectangles were positioned to the left and right of fixation. The two rectangles comprising the L-shapes were separated by an internal discontinuity in the "segmented" (Figure 1, Panels A and C) but not in the "unsegmented" (Figure 1, Panels B and D) display condition. At a viewing distance of $50 \mathrm{~cm}$, the longer rectangle of each L-shape subtended $7.2^{\circ} \times 1.8^{\circ}$ and the smaller rectangle $2.8^{\circ}$ $\times 2.2^{\circ}$ of visual angle. The fixation cross was black and measured $0.8^{\circ} \times 0.8^{\circ}$. The cue was a white outline square subtending $0.6^{\circ} \times$ $0.6^{\circ}$ (contours measuring $0.2^{\circ} \times 0.2^{\circ}$ ) and the target was a filled white square subtending $0.8^{\circ} \times 0.8^{\circ}$ of visual angle. The whole display from end to end was $13.2^{\circ}$ high and $10.8^{\circ}$ wide. The distance between cues and targets in CT Locations 2-4 (see Design section) was $4.5^{\circ}$, irrespective of whether the targets appeared on the same or on a different object from the cue.

In the object-absent condition participants viewed sequences of the fixation cross, the cue and the target appearing on an otherwise empty screen. Cues and targets were presented in exactly the same positions as in the object-present condition.

\section{Design}

The experiment used a within-subjects design with the following factors: object, display orientation, segmentation, SOA, and CT location. Object had two levels: object present and object absent. Display orientation had two levels: $+45^{\circ}$ and $-45^{\circ}$. Segmentation had two levels: segmented and unsegmented. SOA had two levels: 820 and 1,220 msec. CT location had four levels. In the object-present condition, targets appeared randomly, and with equal probability, in each of the following four CT configurations (Figure 2):
CT Location 1. The target appeared on the same object, same part, and at the same location as the cue. This is the standard cuing condition in typical studies of IOR.

CT Location 2. The target appeared on the same object, same part, but at a different location from the cue.

CT Location 3. The target appeared on the same object but on a different part from the cue.

CT Locations 2 and 3 allowed us to examine the spread of inhibition across object structure (e.g., Reppa \& Leek, in press).

CT Location 4-uncued baseline. The target appeared on the corresponding part of a different object, and at the same corresponding location, as the cue.

Responses in CT Location 4 compared with those in CT Location 1 provide the standard measure of IOR.

There were also two types of different object filler trials involving other CT locations (Figure 2). On these trials targets always appeared on the uncued object, either on the corresponding part to the cued location (Filler 1) or on a different part (Filler 2). CT distance in the filler trials was not equated to CT distance in CT Locations 2-4. They were therefore excluded from the analysis. All of the above CT configurations (CT Locations 1-4 and two filler locations) were identical in the segmented and unsegmented object-present and object-absent displays (Figure 2). The task, in both object conditions, was to respond by a simple keypress to the onset of a prespecified target on the screen.

The participants completed 10 practice trials followed by 340 experimental trials in the object-present condition and 160 trials in the object-absent condition. Thirty percent of all trials (100 trials in the object-present and 40 trials in the object-absent condition) were "no-target" trials. In the object-present condition, the remaining 240 "target" trials consisted of 10 trials for each CT location
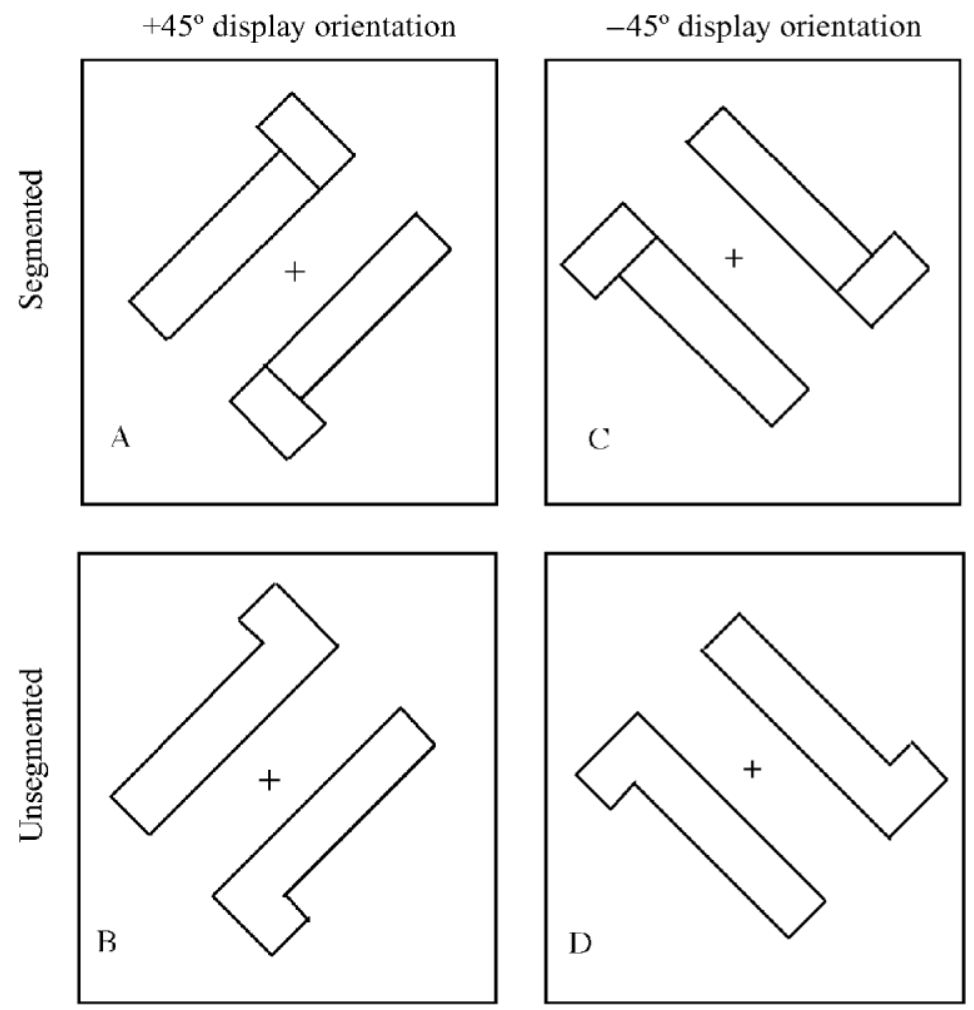

Figure 1. Examples of the L-shaped stimuli used in the object-present condition. 


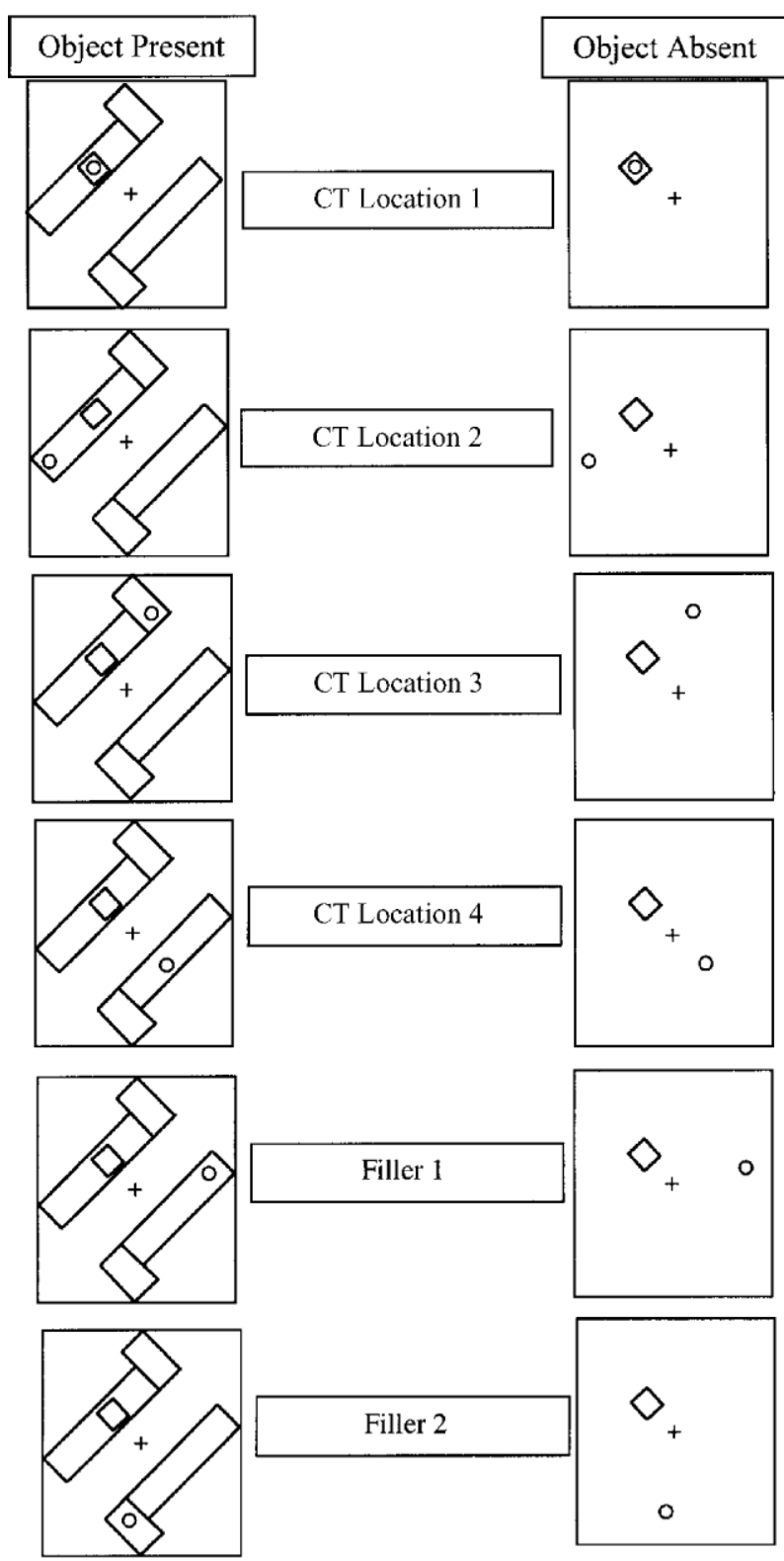

Figure 2. An illustration of the four cue-target (CT) location conditions (three within objects and one between objects) and the two filler trials in this study. The display orientation depicted

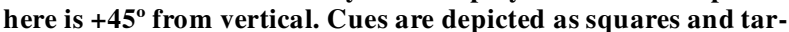
gets as circles. The $\mathrm{CT}$ location conditions were the same for the object-present and object-absent conditions.

(CT Locations 1-4 and two filler locations) for each type of display type (segmented vs. unsegmented) and orientation $\left(+45^{\circ},-45^{\circ}\right)$ collapsed across SOA $(10 \times 6 \times 2 \times 2=240)$. In the object-absent condition, the remaining 120 target trials consisted of 10 trials for each CT location (including filler locations) at each display orientation collapsed across SOA $(10 \times 6 \times 2=120)$.

The presentation of trials in the segmented and unsegmented object displays was randomized within the object-present condition. The presentation order of the object-present and object-absent conditions was counterbalanced using an $\mathrm{AB}-\mathrm{BA}$ between-subjects procedure: Half the participants viewed the object-present condition first $(\mathrm{AB})$ and the other half viewed the object-absent condition first (BA).

\section{Procedure}

The trial procedure is illustrated in Figure 3. At the beginning of each trial a fixation cross was shown in the center of the monitor. After 1,000 msec, two L-shapes were simultaneously presented on each side of the fixation cross. Following a further 1,000-msec delay the peripheral cue appeared at one of two locations in the middle of the two L-shapes. Cue location was random and equiprobable. Cue duration was $90 \mathrm{msec}$. At intervals of either 300 or $500 \mathrm{msec}$ from cue offset, the central fixation cross changed from black to white for a period of $130 \mathrm{msec}$ and then reverted to black until the end of the trial (central refixation). After a further delay of 300 or $500 \mathrm{msec}$, the target was presented at one of the four possible cue locations. The target remained visible for $1,000 \mathrm{msec}$ or until the response key (lowercase $b$ ) was depressed. The target subsequently appeared at one of six possible CT locations (Figure 2).

For the object-absent displays, the sequence of events was identical except that there were no objects on the screen and the cues and targets were presented at the same locations as in the objectpresent condition.

The participants were informed that the white outline square (the cue) was not predictive of the location of the subsequent target. They were instructed to press the response key as soon as they detected the target and to withhold their response when no target was presented. A $500-\mathrm{Hz}$ tone was generated by the computer if the participants failed to withhold their response on the no-target trials. In such cases, the trial was considered an error. The importance of fixating on the cross was stressed during the practice period and just before the experiment commenced.

\section{Results and Discussion}

The aims of the analyses were to determine whether (1) the object-based component of IOR is greater than the pure location-based component in static displays and (2) the magnitude of object-based IOR can be modulated by object-specific properties of the displays. Such findings would support the claim that object-based IOR reflects the operation of functionally distinct object- and location-based inhibitory processes (e.g., Jordan \& Tipper, 1998; Tipper \& Weaver, 1998; Weaver et al., 1998), rather than a single-component mechanism, as suggested by McAuliffe et al. (2001). The results showed that (1) IOR was larger in the object-present than in the object-absent displays, and (2) IOR was modulated by object-internal structure. To support these findings we first compared the magnitude of IOR in the object-present versus the object-absent displays. Second, we examined the change in the magnitude of object-based IOR in relation to object internal structure.

IOR effects in object-present versus object-absent displays. RTs greater than $700 \mathrm{msec}$ (slow) or less than $200 \mathrm{msec}$ (anticipatory), as well as trials with responses to no-target trials were discarded from the data. These exclusions made up only $1.4 \%$ of the data for objectpresent trials and $1.1 \%$ for object-absent trials.

Mean RTs for each CT location condition for the objectpresent (segmented and unsegmented) and object-absent trials are shown in Table 1. The mean IOR effects (CT Locations 1, 2, and 3 minus CT Location 4) are shown in Figure 4.

A 2 (object present segmented and object absent) $\times 4$ $\left(\right.$ CT Locations 1-4) $\times 2$ (display orientation, $+45^{\circ}$ and $\left.-45^{\circ}\right) \times 2$ (SOA: 820 and $\left.1,220 \mathrm{msec}\right)$ repeated measures analysis of variance (ANOVA) revealed significant 


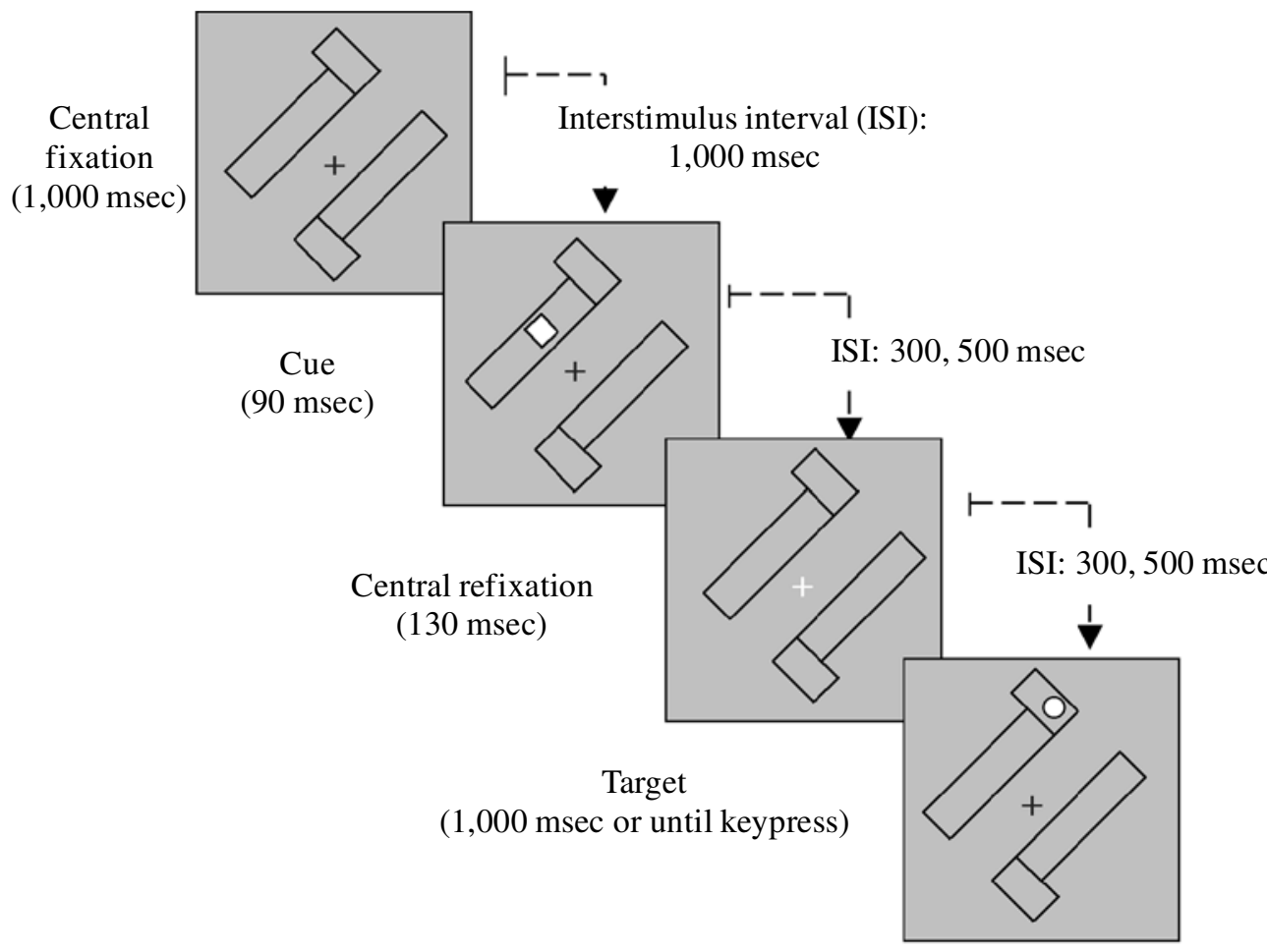

Figure 3. An illustration of a same object/different part trial, when the $L$-shapes were presented at $+\mathbf{4 5}^{\circ}$ orientation. The target was presented within the same object but at a different part from the cue. Here for illustration purposes only the cue is depicted as a square and the target as a circle.

main effects of object $[F(1,33)=4.8, p=.03]$ and $\mathrm{CT}$ location $[F(3,99)=50.0, p=.0001]$. The main effects of SOA and display orientation were not significant $[F(1,33)<1$, n.s., and $F(1,33)<1$, n.s., respectively]. The predicted interaction between object present versus object absent and CT location was highly significant $[F(3,99)=10.9, p=.0001]$. In the object-present segmented trials the IOR effect (CT Locations 1-3 minus CT Location 4) was significant for all three within-object conditions [CT Location $1, t(33)=-12.1, p=.0001 ; \mathrm{CT}$ Location $2, t(33)=-9.7, p=.0001 ; \mathrm{CT}$ Location $3, t(33)=$ $-8.9, p=.0001]$. The IOR effect in the corresponding conditions in the object-absent trials was also significant $[t(33)=-5.1, p=.0001, t(33)=-2.7, p=.008$, and $t(33)=-2.8, p=.006$, respectively, for CT Locations 1 , 2 , and 3$]$.

The significant object $\times$ CT location interaction was further examined in planned comparisons of the difference in the magnitude of IOR (CT Locations 1-3 minus CT Location 4) between object-present segmented and objectabsent displays at each CT location. The results showed significantly larger IOR effects in the object-present versus object-absent condition at all three CT locations [CT Location $1, t(33)=3.4, p<.002 ;$ CT Location $2, t(33)=3.8$, $p<.0001 ;$ CT Location 3, $t(33)=3.2, p<.003$ ] .

A second 2 (object present unsegmented and object absent $) \times 4$ (CT Locations 1-4) $\times 2$ (display orientation, $+45^{\circ}$ and $\left.-45^{\circ}\right) \times 2($ SOA of 820 and $1,220 \mathrm{msec})$ repeated measures ANOVA was undertaken to examine IOR in the unsegmented object relative to object-absent displays. There were significant main effects of object $[F(1,33)=7.1, p=.008]$ and CT location $[F(3,99)=$ $45.0, p=.0001]$. The main effects of SOA and display orientation were not significant $[F(1,33)<1$, n.s., and $F(1,33)<1$, n.s., respectively]. Again, the interaction between CT location and object present versus object absent was significant $[F(3,99)=7.0, p=.0001]$. In the objectpresent unsegmented trials the IOR effect was significant at all three within-objects CT locations [CT Location $1, t(33)=-10.0, p=.0001 ;$ CT Location $2, t(33)=$ $-7.0, p=.0001$; and CT Location $3, t(33)=-8.4, p=$

Table 1

Mean Reaction Times (RTs) for the Four Cue-Target (CT) Location Conditions and the Two Types of Filler CT Location Conditions in Object-Present and Object-Absent Trials

\begin{tabular}{lccc}
\hline & \multicolumn{3}{c}{ Display } \\
\cline { 2 - 3 } Condition & \multicolumn{2}{c}{ Object Present } & \\
\cline { 2 - 3 } & Segmented & Unsegmented & Object Absent \\
\hline CT Location 1 & 384 & 385 & 365 \\
CT Location 2 & 358 & 366 & 348 \\
CT Location 3 & 368 & 367 & 353 \\
CT Location 4 & 326 & 331 & 337 \\
Filler 1 & 340 & 345 & 343 \\
Filler 2 & 340 & 342 & 345 \\
\hline
\end{tabular}

Note-Filler trials were not used in the calculation of main effects due to the CT spatial proximity confounds (also see Design section). 


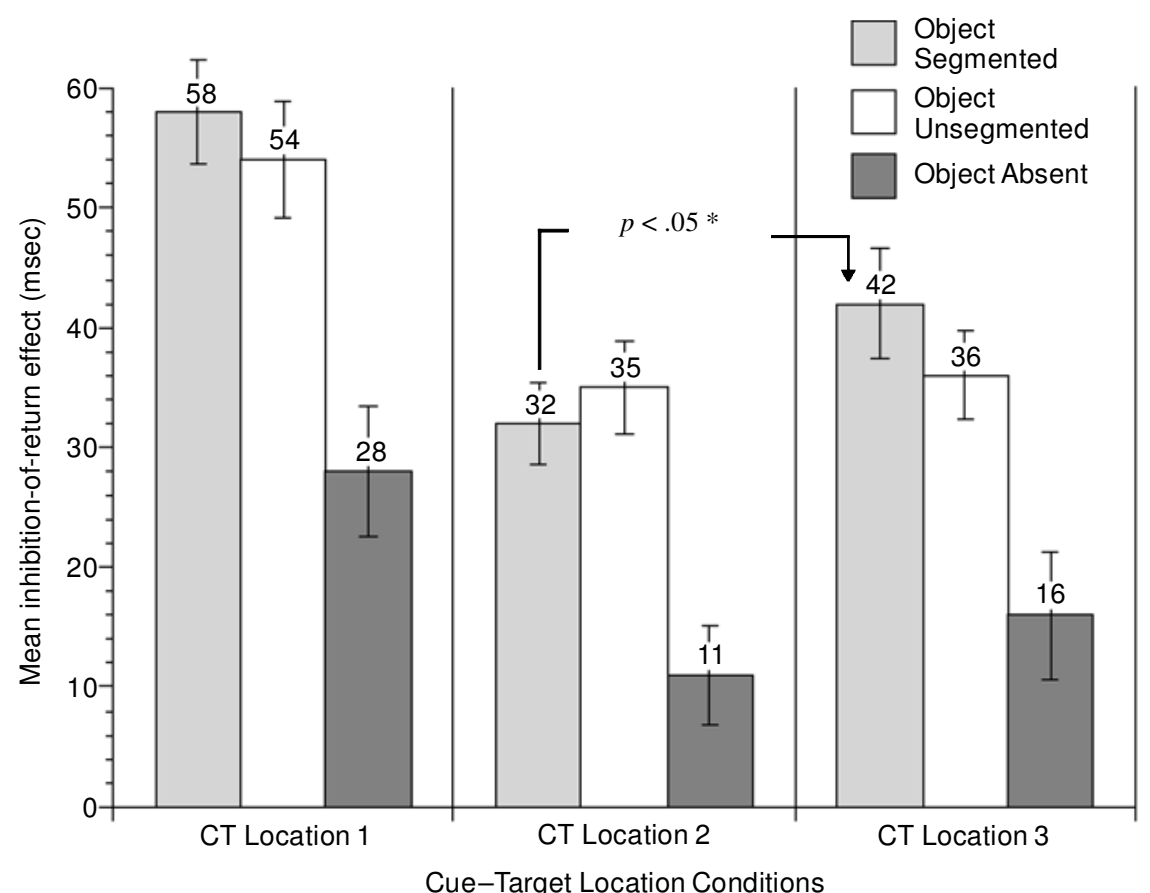

Figure 4. Mean inhibition-of-return (IOR) effects are the product of cue-target (CT) Locations 1, 2, and 3 minus CT Location 4 (uncued baseline). These IOR effects are shown for object-present (segmented and unsegmented) and object-absent conditions. Error bars represent standard error.

$.0001]$. In the object-absent trials the IOR effects were also significant, as shown above.

Planned contrasts to investigate the CT location $\times$ object interaction showed that IOR was larger for objectpresent unsegmented trials than for object-absent trials at all three CT locations [CT Location $1, t(33)=3.0, p<$ .004 ; CT Location 2, $t(33)=2.8, p=.008$; CT Location $3, t(33)=2.5, p<.01] .{ }^{1}$

The modulation of IOR across object-internal structure. We also examined the modulation of objectbased IOR as function of CT location in the segmented versus unsegmented (object-present) displays. These analyses were motivated by the recent finding of Reppa and Leek (in press) that object-based IOR can be modulated by the location of cues and targets in relation to object-internal structural features-providing further evidence for a component of IOR that is sensitive to object-specific properties.

Initial analyses showed no main effects or interactions of task order, orientation, or SOA. A 3 (CT Locations 1-3) $\times 2$ (segmentation: segmented vs. unsegmented) repeated measures ANOVA was carried out on the mean IOR effects in the three within-object CT locations (CT Locations 1-3). This showed a significant main effect of CT location $[F(2,66)=27.7, p<.0001]$ and a significant main effect of segmentation $[F(1,33)=4.97, p<.03]$. Consistent with the findings of Reppa and Leek (in press), planned comparisons showed that, in the segmented displays, IOR was significantly larger in CT Location 3
(42 $\mathrm{msec})$ than in CT Location $2[32 \mathrm{msec} ; t(33)=2.1$, $p<.05]$. In contrast, there was no significant difference in IOR between the same two CT locations in the unsegmented displays $[t(33)=1.2$, n.s.]. Thus, object-based IOR is significantly larger when cues and targets are separated by an object-internal structural discontinuity (defined by an intervening contour segment) than when they both appear on the same side of the internal feature.

The present data also allowed us to examine a further issue that was not addressed in the Reppa and Leek (in press) study. While the present results (like those of Reppa \& Leek) show that the magnitude of IOR is different between CT Locations 2 and 3 in the segmented displays, one might argue that this difference is not dependent on object-internal structure per se (i.e., the presence of an intervening structural discontinuity), but rather reflects heterogeneity in the spatial distribution of inhibition across the visual field (e.g., Bennett \& Pratt, 2001; Pratt, Spalek, \& Bradshaw, 1999). If so we might expect that the same difference in IOR would also be found between CT Locations 2 and 3 in the object-absent displays. However, this was not the case. In the objectabsent displays there was no significant difference in IOR between CT Locations 2 and $3[t(33)<1.0$, n.s.].

\section{DISCUSSION}

The main findings can be summarized as follows: (1) IOR was significantly larger in object-present (mean 
IOR $=40 \mathrm{msec}$ ) than in object-absent displays (mean IOR $=18 \mathrm{msec}$ ). This effect was found for two different object types (segmented and unsegmented) relative to pure location trials, and it is remarkably similar to the original observations of Jordan and Tipper (1998). (2) Object-based IOR was larger when cues and targets were separated by an object-internal structural discontinuity (that is, a "part" boundary) than when cues and targets appeared on the same object part. In addition, this difference was found only on segmented object-present trials and not on object-absent trials.

\section{Object- and Location-Based IOR in Static Displays}

The main aim of this paper was to examine the recent claim by McAuliffe et al. (2001) that larger IOR effects for cued objects over pure locations in static displays are limited to situations where (1) object and no-object trials are randomized rather than blocked, (2) relatively short CT SOAs are used ( $<400 \mathrm{msec})$, and (3) where both "object" and "no-object" CT conditions are probed in the same display. Our data undermine this claim. We found larger IOR effects for cued objects over pure locations using a blocked design, relatively long SOAs (820 and 1,220 msec), and where cued object and cued location trials were measured using different displays.

On the basis of their data, McAuliffe et al. (2001) proposed that object- and location-based IOR effects might be better explained by a single IOR mechanism that operates on objects and locations in the same way, rather than by a two-component model in which inhibition is assumed to operate independently within location- and object-based frames of reference (e.g., Jordan \& Tipper, 1998). The latter account predicts that IOR should be larger for cued objects than for pure locations in static displays through summation of location- and object-based inhibition. The present data support this prediction and show that separating object and no-object trials, and using longer SOAs, is not the cause of the reduced object-based IOR found by McAuliffe et al. When objects are more complex, as in the present study, rather than simple placeholder boxes, when they vary in orientation, and when cues and targets are presented in a variety of loci, the presence of objects in the display influences IOR. In contrast, when objects are less salient (e.g., less complex, fixed in orientation), and when CT locations are more predictable, object-based effects are likely to be attenuated because they are easier to ignore; that is, task performance (i.e., target detection) is less dependent on the inhibition of "irrelevant" objects in the display. This may underlie the absence of larger object-based IOR in the McAuliffe et al. study.

While the present data undermine the empirical motivation for the single-component model of location- and object-based IOR, some other problematic aspects of this account also merit discussion. One important assumption is that objects attract inhibition more strongly than empty locations when an object is present in the display. In fact, this assumption is central to the singlecomponent model because without it the hypothesis does not explain why larger IOR effects have been reported for objects over pure locations in previous studies (e.g., Jordan \& Tipper, 1998). To accommodate the present data, within the single-component account, one might argue that it is sufficient to strengthen this assumption so that objects always attract more inhibition than empty locations, regardless of whether objects and locations are probed in the same or in different displays.

However, if this stronger assumption is made then it would not be clear how the single-component model could be distinguished theoretically from the two-component account, in which it is assumed that object- and locationbased IOR operate over functionally distinct frames of reference. The assumption that objects attract more inhibition than locations would amount to an admission that objects and locations may be inhibited independently. Finally, it should be noted that the single-component model provides no explanation for how both location- and object-based IOR can be observed simultaneously in dynamic displays (Tipper et al., 1999; Tipper et al., 1994; Weaver et al., 1998), or in cases where object-based frames of reference (i.e., in moving displays) act to eliminate the effect of location-based frames of reference on the magnitude of IOR (e.g., Christ, McCrae, \& Abrams, 2002).

\section{The Modulation of Object-Based IOR by Object-Internal Structure}

Our data also provide further evidence that IOR can be modulated by object-internal structure. In the objectpresent condition, object-based IOR is larger when cues and targets are separated by an object-internal shape feature (i.e., a "part" boundary) than when they appear on the same side of the discontinuity. This pattern of modulation was originally reported by Reppa and Leek (in press), but the present data also speak to an issue that was not addressed in the Reppa and Leek study. Although IOR is larger for CT locations that are separated by an internal structural feature (CT Location 3 ) than for locations that are not separated (CT Location 2) - even though the distance between cues and targets is identical between conditions-one might argue that this difference is related to other spatial factors, such as an uneven "distribution" of inhibition across the visual field (e.g., Bennett \& Pratt, 2001; Pratt et al., 1999). This possibility was addressed in the present study by showing that no difference in IOR is found between CT Locations 2 and 3 in the object-absent displays. This shows that the difference in IOR between these same locations in the segmented object displays is not related to the spatial locations of the CT pairs independently of the objects in which those locations are probed.

This demonstration of the modulation of object-based IOR provides further evidence that object- and locationbased IOR are functionally dissociable. It also has implications for hypotheses about the kinds of object representations that mediate attentional selection. A pure location-based account of IOR would predict that inhibition should decrease as the distance between cues and targets increases. The modulation effect found in the seg- 
mented object displays shows that this is not necessarily the case: The magnitude of IOR is determined by objectinternal structure (e.g., a "part" boundary), as well as CT distance (e.g., within a single-object component). This finding reinforces the main argument in this paper that location- and object-based IOR are functionally independent (or at least partially so). In addition, the modulation effect suggests that the processes that mediate IOR operate over object shape representations that contain local (i.e., internal) object structure, as argued in Reppa and Leek (in press). One explanation for this pattern of modulation might lie in the potential differential spread of facilitation and inhibition over object structure (Reppa \& Leek, in press). For example, a target that appears on the same part as the cue may be subject to both facilitation (through perceptual grouping) and inhibition, depending on the CT interval (e.g., Mari-Beffa, Houghton, Estevez, \& Fuentes, 2000). Thus, the attenuation of IOR within a single-object component might reflect a summation of inhibition and facilitation. However, at present, relatively little is known about how inhibitory and facilitatory mechanisms of selection interact with object shape representations and their structural properties (see also Gibson \& Egeth, 1994; Iani, Nicoletti, Rubichi, \& Umiltà, 2001; Lavie \& Driver, 1996; Vecera, Behrmann, \& Filapek, 2001; Vecera, Behrmann, \& McGoldrick, 2000).

In summary, the present data are consistent with previous work showing that locations and objects can be inhibited independently (e.g., Christ et al., 2002; Jordan \& Tipper, 1998). These findings are consistent with the two-component model of IOR, which assumes that objectand location-based IOR operate over functionally distinct reference frames. Furthermore, the results also show that IOR is influenced by the internal structure of objects-a finding that is also consistent with the view that IOR may interact with structured shape representations independently of object locations in space.

\section{REFERENCES}

Bennett, B. J., \& Pratt, J. (2001). The spatial distribution of inhibition of return. Psychological Science, 12, 76-80.

Christ, S. E., McCrae, C. S., \& Abrams, R. A. (2002). Inhibition of return in static and dynamic displays. Psychonomic Bulletin \& Review, 9, 80-85.

Cohen, J. D., MacWhinney, B., Flatt, M., \& Provost, J. (1993). PsyScope: A new graphic interactive environment for designing psychology experiments. Behavior Research Methods, Instruments, \& Computers, 25, 257-271.

Gibson, B. S., \& EGETh, H. (1994). Inhibition of return to object-based and environment-based locations. Perception \& Psychophysics, 55, 323-339.

IAni, C., Nicoletti, R., Rubichi, S., \& Umiltà, C. (2001). Shifting attention between objects. Cognitive Brain Research, 11, 157-164.

JoRdAN, H., \& TIPPER, S. P. (1998). Object-based inhibition of return in static displays. Psychonomic Bulletin \& Review, 5, 504-509.

JoRdAN, H., \& TipPER, S. P. (1999). Spread of inhibition across an object's surface. British Journal of Psychology, 90, 495-507.

LAVIE, N., \& DrIVER, J. (1996). On the spatial extent of attention in objectbased visual selection. Perception \& Psychophysics, 58, 1238-1251.

Mari-Beffa, P., Houghton, G., Estevez, A. F., \& Fuentes, L. J. (2000). Word-based grouping affects the prime-task effect on se- mantic priming. Journal of Experimental Psychology: Human Perception \& Performance, 26, 469-479.

MAYLOR, E. (1985). Facilitatory and inhibitory components of orienting in visual space. In M. I. Posner \& O. S. M. Marin (Eds.), Attention and performance XI (pp. 189-204). Hillsdale, NJ: Erlbaum.

McAuliffe, J., Pratt, J., \& O’ Donnell, C. (2001). Examining locationbased and object-based components of inhibition of return in static displays. Perception \& Psychophysics, 63, 1072-1082.

Müller, H. J., \& Von Mühlenen, A. (1996). Attentional tracking and inhibition of return in dynamic displays. Perception \& Psychophysics, 58, 224-249.

Posner, M., \& Cohen, Y. (1984). Components of visual orienting. In H. Bouma \& D. G. Bouwhuis (Eds.), Attention and performance X: Control oflanguage processes (pp. 531-556). Hillsdale, NJ: Erlbaum.

Pratt, J., SpaleK, T., \& Bradshaw, E. (1999). The time to detect targets at inhibited and noninhibited locations: Preliminary evidence for attentional momentum. Journal of Experimental Psychology: Human Perception \& Performance, 25, 730-746.

REPPA, I., \& LEEK, E. C. (in press). The modulation of inhibition-ofreturn by object-internal structure: Implications for theories of objectbased attentional selection. Psychonomic Bulletin \& Review.

Tipper, S. P., Driver, J., \& Weaver, B. (1991). Object-centered inhibition of return of visual attention. Quarterly Journal of Experimental Psychology, 43A, 289-298.

TipPER, S. P., Jordan, H. \& WEAVER, B. (1999). Scene-based and objectcentered inhibition of return: Evidence for dual orienting mechanisms. Perception \& Psychophysics, 61, 50-60.

TipPER, S. P., \& WEAVER, B. (1998). The medium of attention: Locationbased, object-centered or scene-based? In R. Wright (Ed.), Visual attention (pp. 77-107). New York: Oxford University Press.

Tipper, S. P., Weaver, B., Jerreat, L. M., \& Burak, A. L. (1994). Object-based and environment-based inhibition of return of visual attention. Journal of Experimental Psychology: Human Perception \& Performance, 20, 478-499.

Vecera, S. P., Behrmann, M., \& Filapek, J. C. (2001). Attending to the parts of a single object: Part-based selection limitations. Perception \& Psychophysics, 63, 308-321.

Vecera, S. P., Behrmann, M., \& McGoldrick, J. (2000). Selective attention to the parts of an object. Psychonomic Bulletin \& Review, 7, 301-308.

WeAVER, B., Lupiáñez, J., \& WATSOn, F. L. (1998). The effects of practice on object-based, location-based and static-display inhibition of return. Perception \& Psychophysics, 60, 993-1003.

\section{NOTE}

1. Since there were twice as many trials in the object-present than in the object-absent condition, we also separately analyzed data from the first 160 trials of the object-present displays (yielding approximately 15 trials per CT location in each segmentation condition) when the objectabsent displays were viewed first. The results replicated those obtained from the whole object-present data set. A 4 (CT Locations 1-4) $\times 2$ (object present segmented and object absent) repeated measures ANOVA showed a nonsignificant main effect of object type $[F(16)<1$, n.s.], a significant main effect of CT location $[F(16)=23.2, p=.001]$, and a significant CT location $\times$ object type interaction $[F(16)=3.1, p=$ .03]. Planned comparisons revealed a significant difference in the IOR effect between the object-present $(58,35$, and $49 \mathrm{msec})$ and object-absent displays $(34,12$, and $19 \mathrm{msec})$ at CT Locations $1-3[t(16)=2.9, p=$ $.002, t(16)=3.7, p=.001$, and $t(16)=4.2, p=.0001$, respectively]. Similarly, a 4 (CT Locations 1-4) $\times 2$ (object present unsegmented and object absent) repeated measures ANOVA revealed a nonsignificant main effect of object type $[F(16)<1$, n.s.], a significant main effect of CT location $[F(16)=25.2, p=.001]$, and a significant interaction between the two factors $[F(16)=2.3, p=.04]$. The IOR effects for CT Locations $1-3$ in the object-present displays $(53,35$, and $28 \mathrm{msec})$ was significantly larger than IOR in the object-absent displays $(34,12$, and $17 \mathrm{msec})$ $[t(16)=2.6, p=.003, t(16)=3.3, p=.001$, and $t(16)=1.8, p=.04]$.

(Manuscript received April 9, 2002; revision accepted for publication October 4, 2002.) 